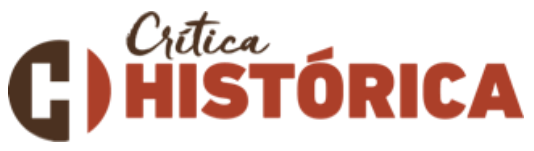

\section{Modelos anarquistas de legitimidade}

Anarchist models of legitimacy

Peterson Roberto da Silva*

Resumo: A legitimidade é uma relação entre sujeito e objeto, com base em um conjunto de valores e crenças, que estabelece um não-conflito (compreendendo tanto a ausência de conflito quanto seu encerramento). Estados buscam legitimar (estabelecer uma ausência de conflito sobre) sua prerrogativa exclusiva de encerrar conflitos violentamente. Alguma medida de não-conflito é essencial ao funcionamento de qualquer grupo, e um modelo anarquista de legitimidade teria por base o questionamento da dinâmica bélica / mercadológica / competitiva de relações sociais, o princípio de ação direta e a ética de coerência entre meios e fins, gerando a defesa de métodos não-violentos de resolução de conflitos. Dentro deste modelo mais amplo defino dois subtipos que surgem de divergências quanto a questões identitárias e organizacionais: o modelo de assembleia e o modelo de rede.

Palavras-chave: Anarquismo; Legitimidade; Ação direta.

Abstract: Legitimacy is a relation between subject and object, based on a set of values and beliefs, which establishes a non-conflict (comprising both the absence of conflict and its closure). States seek to legitimize (establish an absence of conflict over) their exclusive prerogative to terminate violent conflicts. Some measure of non-conflict is essential to the functioning of any group, and an anarchist model of legitimacy would be based on questioning the bellicose / market / competitive dynamics of social relations, the principle of direct action, and the ethics of coherence between means and ends, generating the defence of non-violent methods of conflict resolution. Within this broader model I define two subtypes that arise from disagreements regarding identity and organizational issues: the assembly model and the network model.

Keywords: Anarchism; Legitimacy; Direct action.

\footnotetext{
* Graduado em Ciências Sociais pela Universidade Federal de Santa Catarina (UFSC) (2015). Mestre em Sociologia Política pela UFSC (2018). Atualmente doutorando em Sociologia Política pela UFSC (bolsista CNPq), com sanduíche na Loughborough University (Reino Unido) (bolsista Capes).
} 


\section{C) Gitcastórica}

Introdução

A legitimidade é "um dos problemas mais antigos na história intelectual da civilização ocidental” ' (ZELDITCH JR., 20oI, p. 33). O anarquismo é um movimento político comparativamente recente. Neste artigo, delineio um conceito abrangente de legitimidade, exponho de que modo ele pode representar um problema para anarquistas, e como através do conceito de ação direta pode-se identificar modelos de legitimidade compatíveis com a filosofia política ácrata.

É fortuito definir de antemão o que se entenderá por anarquismo. São comuns as abordagens desta tradição intelectual que a descrevem como uma tendência perene da humanidade, nos contextos geográficos e temporais mais dispersos (GRAEBER, 20II, p. 9IO; NEWMAN, 20I0, p. I7; ROCKER, 2009, p. 8), porém isto sempre leva ao perigo metodológico do anacronismo. Sendo assim, as fontes e referências que abordarei como anarquistas são as de uma "vertente do movimento trabalhista originada em meados do século XIX na Europa”, que defende um "programa socialista para a transformação política" (opondo-se a "todas as formas de dominação e hierarquia") que se diferencia "de suas variedades marxista e reformista" a partir de uma "preocupação especial com a coerência entre meios e fins", sendo que "dentro desse consenso geral" existe "grande diversidade, mas também suficiente coerência para diferenciar sua corrente principal, socialista, de suas tendências individualistas mais marginais" (COHN, 2006, p. I4-I5). Além disso, mesmo dentro dessas marginalidades não se encontram ideologias como o “anarcocapitalismo" ou o "anarquismo nacional”, exclusão defendida por todo estudo sério e criterioso do anarquismo (WILSON, 20II, p. I7; GRAHAM, 20I8, p. 44; KINNA, 20I9, p. 8).

\section{Um breve histórico de discussões sobre a legitimidade}

Weber (1978, p. 53) associa a legitimidade às razões pelas quais pessoas em situação de dominação obedecem a ordens. Enquanto o poder está associado à "probabilidade de que um ator em uma relação social estará em posição de executar sua vontade apesar de resistência, não importando seu fundamento", a dominação está associada à "probabilidade de que um comando com um dado conteúdo específico será obedecido por um dado grupo de pessoas" por conta de sua adesão (CADEMARTORI, I997, p. I34). A diferença estaria no mínimo de "aceitação voluntária" que toda dominação genuína 


\section{C) Hitcostórica}

implicaria (WEBER, I978, p. 212). A partir desse enquadramento, Suchman (1995, p. 573) define a legitimidade como "uma presunção ou percepção generalizada de que as ações de uma entidade são desejáveis ou apropriadas no contexto de algum sistema socialmente construído de normas, valores, crenças e definições" (SUCHMAN, I995, p. 574). Um aspecto importante dessa definição é que a legitimidade é generalizada, isto é, resiliente a eventos adversos particulares, ainda que dependa de um histórico de eventos (uma organização pode desviar de padrões sociais, e ainda ser vista como legítima, se tais desvios forem vistos como exceções). Assim, a legitimidade é criada subjetivamente: uma organização pode mantê-la, apesar de um "desvio", não só porque o desvio é tomado por exceção, mas por não ser notado. A legitimidade existe quando um grupo como um todo aceita ou apoia um padrão de comportamento como um todo; as reservas de "qualquer observador em particular" sobre "qualquer comportamento em particular", bem como as que os observadores "poderiam vir a ter, caso prestassem mais atenção", são relativamente irrelevantes (SUCHMAN, I995, p. 574).

Já para Beetham (I99I, p. 3), o poder é legítimo quando "é adquirido e exercido de acordo com regras justificáveis, e com evidências de consentimento". Beetham não vê essa definição como compatível com a weberiana, porque a partir desta seria impossível fazer um argumento moral ou racional sobre a legitimidade que não fosse uma espécie de "pesquisa de opinião" quanto à proporção em que uma determinada população acredita na legitimidade dos arranjos vigentes de poder (BEETHAM, I99I, p. 8-9). O problema fundamental da definição weberiana é "encorajar uma ciência social incompetente”, que não provê ferramentas para explicar "por que as pessoas reconhecem a legitimidade do poder em um local e época mas não em outro" (BEETHAM, I99I, p. IO). “Uma dada relação de poder", explica Beetham (I99I, p. II), "não é legítima porque as pessoas acreditam em sua legitimidade, mas porque ela pode ser justificada em termos de suas crenças"; ou, como coloca Zelditch Jr. (200I, p. 48), “a crença em algo é diferente de usar essa crença para justificar que alguma outra coisa é 'certa”. Além disso, é de grande importância a "evidência de consentimento expressa através de ações compreendidas como demonstrações de consentimento dentro das convenções de uma sociedade particular" (BEETHAM, I99I, p. I2).

Há quem argumente que entre os possíveis valores e crenças que balizam a legitimidade, a justiça deveria ser o mais importante. Para a filosofia jurídica do garantismo, por exemplo, a justiça e a validade legal embasam a legitimidade (CADEMARTORI, I997, p. 228); note-se que “o Estado e o Direito não são vistos como 


\section{C) HitcostórRICA}

valores em si mesmos", mas como meios ou instrumentos que só são legítimos à medida que buscam "fins extra-jurídicos úteis, desejáveis, axiológica ou politicamente 'justos"” (CADEMARTORI, I997, p. IO2-IO5). Já para Buchanan (2002), a legitimidade não leva diretamente à autoridade, uma vez que ela pode justificar a agência do agente, mas não a necessidade de obediência de terceiros; em outras palavras, um agente pode ser legítimo em suas ações porque age a partir de um "robusto dever natural de justiça", mas essa legitimidade não significa que outros lhe devam obediência (BUCHANAN, 2002, p. 703). Para Buchanan (2002, p. 713-714), a obrigação de obedecer às leis não vem da obrigação de obedecer a autoridade do Estado, mas de considerar outras pessoas como iguais. $\mathrm{O}$ exercício de poder se legitima assim a partir da justiça, e a obediência, a partir da democracia como princípio moral.

Já outros autores dissociam a justiça da legitimidade com variados graus de intensidade (WILLIAMS; HAWTHORN, 2005; RAWLS, I995, p. I75-I76; PETTIT, 20I2), e a separação é completa no caso dos juspositivistas, para os quais o direito "dispõe de racionalidade própria”, independente, legitimando o poder através de suas propriedades formais (CADEMARTORI, I997, p. 136). Ou seja, a legitimidade nada mais é que a legalidade, e o "julgamento moral dos sujeitos morais" se torna, "descartável" para o “direito objetivo" (CADEMARTORI, I997, p. 2I4). Isto, no entanto, é precisamente a adoção de um valor em si: como na dominação legal-racional weberiana, a lei enquanto tal é valorizada (ou talvez a estabilidade que espera-se estabelecer ao valorizá-la).

Assim, a legitimidade não pode ser conceitualmente identificada à legalidade pois ela não se torna redundante: não se pode renunciar a nenhum dos termos sem prejuízo (ZELDITCH JR., 200I, p. 48-49). O conceito de legitimidade "somente pode ser entendido por referência a valores" (POLIN, I967 apud CADEMARTORI, I997, p. I4I).

Há três pontos importantes a ponderar a partir daqui. Em primeiro lugar, se há uma diferença entre a legitimidade descritiva (existe legitimidade - algo é considerado legítimo agora?) e normativa (o que deveria ser legítimo?). Tanto em um quanto no outro há que se debater o valor do consentimento e do consenso, que é o segundo ponto: uma instituição só é legítima quando há uma crença absoluta em sua legitimidade? Essa crença pode ser aferida a partir da operacionalização do consentimento? Qual o papel do consentimento (culturalmente compreendido) na caracterização de algo como legítimo? Por último - e em conexão com a questão do consenso - o que significa a legitimidade em contextos de conflito? 


\section{C) Histótórica}

Beetham ataca a concepção descritiva da legitimidade (derivada da noção weberiana), mas ela não pode ser facilmente ignorada; a legitimidade como "crença na legitimidade" tem um efeito; ela "explica a estabilidade de qualquer tipo de estrutura, em qualquer nível” (ZELDITCH JR., 200I, p. 40, ênfase no original). Segundo Tyler (200I, p. 4I7-4I8), é mais fácil administrar um grupo (uma sociedade, uma empresa, uma organização) a partir de uma abordagem de legitimidade que a partir de operações de "comando e controle" (segundo a qual "o comportamento das pessoas é principalmente moldado" por suas percepções de "recompensas e punições"), porque estas últimas seriam “custosas, ineficientes e com frequência ineficazes". Esse uso estratégico da legitimidade já pressupõe a consideração de uma dimensão de conflito no próprio conceito; se há quem se beneficie por estabelecer e manter a estabilidade de um sistema, a legitimidade seria "uma estratégia efetiva de geração de influência". O consenso pode deste modo indicar uma dominação, mas se a legitimidade está associada à justeza dos procedimentos da autoridade, como sugere Tyler (2006, p. 416), alguns teóricos analisam que a busca pelo "recurso da legitimidade" faz com que instituições e autoridades busquem ser justas em seus procedimentos. A negociação de consenso, afinal, não é um processo unicamente hierárquico, que ocorre sob controle da liderança e por sua iniciativa; "teorias da legitimidade [...] especificam condições em que surgem pressões para mudar as estruturas existentes", isto é, a "ilegitimidade" torna legítimos os impulsos por "reforma e/ou rebelião", e assim a legitimação funciona como "um mecanismo de mediação entre a estrutura do grupo e as ações dos indivíduos" (ZELDITCH JR., 200I, p. 50).

\section{Conceituando a legitimidade}

Podemos afirmar que a legitimidade se trata de uma relação entre um sujeito, um objeto e um conjunto de valores e crenças, que estabelece o não-conflito. Este conceito, que consegue conciliar as problemáticas expostas acima, não é na verdade único: o "nãoconflito" é uma forma conveniente de abranger dois contextos bastante diferentes, mas igualmente relevantes. O primeiro é o de ausência de conflito: neste caso, o não-conflito existe porque o conflito não existe. $\mathrm{O}$ conflito não foi silenciado, escamoteado ou reprimido; ele simplesmente não está presente para que possa ser silenciado, escamoteado ou reprimido. O segundo caso é o de encerramento de conflito: a legitimidade se coloca, assim, como a busca pelo estabelecimento do não-conflito a partir do processamento do conflito que existe. Questões de perspectiva aqui são essenciais: poder-se-ia dizer, de uma 


\section{C) HitistórRICA}

situação de ausência de conflito, que seu conflito foi encerrado há tanto tempo que o fato de ter existido um dia tornou-se irrelevante; por outro lado, o ideal que regula o impulso de encerramento do conflito é sua erradicação, uma situação em que ele deixa de existir.

É claro que é arriscado associar o consenso à legitimidade. A ausência de conflito manifesto (discordância, altercação física) não significa que ele não existe; pode indicar, ao contrário, uma dominação eficaz, uma violência oculta (Ó LAOGHAIRE, 20I6, p. I6). No entanto, o critério da legitimidade não é a ausência de conflito manifesto, mas a situação que a produz. É preciso diferenciar o não-conflito objetivo, que reflete um não-conflito subjetivo compartilhado, do não-conflito cuja objetividade (como um consenso explícito) se produz por meio da opressão (por tanto, de conflito). De qualquer modo, se a legitimidade se refere inerentemente a uma situação de resolução e estabilidade, do ponto de vista descritivo não há nada mais legítimo do que algo ao qual literalmente ninguém se opõe sem que haja qualquer violência (ou ameaça de violência) envolvida (ou seja, o consenso). Pode-se questionar a partir de que ponto uma tal situação se torna impensável (com uma grande quantidade de pessoas, por exemplo), mas certamente não há padrão conceitual mais alto de legitimidade.

É preciso ressaltar que pensar a legitimidade é pensar o não-conflito mesmo politicamente, num sentido de política enquanto conflito: se é afirmado que o legítimo é, digamos, aquilo que é justo, o que se está dizendo é que as pessoas deveriam aceitar (não entrar em conflito com) o que for justo, além de se rebelar contra, não apoiar, não aceitar (entrar em conflito com), o que é injusto. Para Bobbio e Bovero (I987 apud CADEMARTORI, I997, p. I27), por exemplo, a legitimidade se refere à "determinação dos casos em que se deve obedecer e dos casos em que é lícita a desobediência ou a obediência passiva". Para a corrente teórica autodeclarada "realista política" (WILLIAMS; HAWTHORN, 2005), seria irrelevante (talvez até perigoso) dizer que só é legítimo o que está relacionado a certos valores e crenças, especialmente morais, uma vez que é impossível que se chegue a um consenso não-violento - e no entanto, nesse contexto algum consenso de fundo, em nome da própria estabilidade, seria desejável: algo como a "valorização do pluralismo", ou determinados métodos decisórios. Considera-se especialmente, neste caso, que o conflito tornaria a convivência disfuncional, e entrar em permanente "conflito contra o conflito", por assim dizer (usar apenas da força para gerar obediência) é ineficiente (como visto acima). Ainda assim, teorias políticas que se entendem "realistas", como no campo do liberalismo ou mesmo do conservadorismo, diferenciam-se por rejeitar a possibilidade de alcançar a legitimidade unicamente através de dinâmicas dialógicas e culturais, posto que 


\section{C) HitcostórRICA}

se pode contar com o uso da força; não é por acaso, assim, que tantas teorias normativas de legitimidade no campo da teoria política se preocupam com a justificação do uso da força.

De qualquer modo, para que possa não haver conflito, este precisa ter sido encerrado. A questão é como, e de que maneira este próprio método de encerramento vira objeto de discursos de legitimidade. A legitimidade pode ser pensada como orientação para o não-conflito mesmo no caso em que o conflito é visto como inescapável. É fácil compreender que não há sociedade "que não veja a vida humana como fundamentalmente um problema", comenta Graeber (20II, p. 57); "a existência do trabalho, o sexo e a reprodução são encarados como preocupações", mas há também o fato de que "os desejos humanos são sempre mutáveis" e de que "todos nós morreremos um dia”. É difícil sustentar situações de não-conflito a longo prazo porque grupos "são com frequência heterogêneos", "a estabilidade com frequência implica rigidez" (um problema, já que isso dificuldade a "responsividade a transformações") e, por fim, a "institucionalização frequentemente gera sua própria oposição" (SUCHMAN, I995, p. 594). Se tudo isso faz do conflito uma parte inescapável da existência humana, por outro lado não significa que a vida se resuma a isso. A legitimidade é uma categoria essencial justamente porque estamos constantemente pensando na estabilidade; em como obtê-la, como mantê-la, até que ponto é benéfico tê-la - em suma, que tipo de estabilidade é preferível.

Somente se pode superar o conflito (o que existe, e fazê-lo temporariamente, tanto quanto possível) através de mecanismos que o "processem", isto é, instituições e procedimentos que canalizem a diversidade social em direção a um estado de não-conflito, possibilitando a ação coletiva e a estabilidade de uma certa rede de agentes e práticas. A questão é a natureza de tais mecanismos. Um método que prolongue o conflito por não aceitar seu desfecho violento pode ser legitimado tendo em vista outros princípios, que sejam mais valorizados que a estabilidade. No caso da "força", ela própria precisa ser justificada pois se trata de algo inerentemente conflituoso - ou seja, faz-se necessário explicar como uma força é diferente de (e melhor que) outras, e porque (a resolução violenta de) alguns conflitos são toleráveis em nome de um não-conflito mais abrangente. Assim, chega-se a um não-conflito quanto ao uso da força para que ela possa encerrar conflitos, gerando a situação de estabilidade previamente definida como benéfica. Isso não necessariamente opõe "moralistas" a "realistas" políticos, pois aqueles podem também preconizar o uso da força; separa, em vez disso, alguns critérios morais de outros. Para toda uma ala de teóricos políticos, a inevitabilidade do conflito significa mais que a dificuldade de resolvê-lo; significa que apenas a força assegura momentos de não-conflito, segurança e 


\section{C) HitconTórica}

cooperação. A busca pela legitimidade torna-se indireta; é preciso estabilizar o próprio método de estabelecimento do não-conflito, o que motiva as teses normativas que buscam explicar que uma instituição como o Estado deve ser aceita (porque leva à previsibilidade, ou à segurança, ou à justiça, ou à igualdade, ou à liberdade, ou à organização da vontade da maioria, e assim por diante). O que se busca com a legitimidade é portanto o não-conflito quanto a uma determinada situação: se as pessoas legitimam o voto majoritário e o uso da força para fazer valer seus resultados, é isto que será legítimo em meio aos inúmeros conflitos pontuais que são resolvidos (gerando novas legitimidades pontuais) por meio dele. A lógica não é infinitamente recursiva: se o Estado não fornece razões para sua existência, seu direito de exercício de força baseia-se completamente na força, e assim não há motivo para ser visto pelos dominados como merecedor de louros em vez de bombas. Em outras palavras, não haveria legitimidade porque haveria um conflito, e um que só se encerraria por meio de mais conflito.

\section{Legitimidade como problema}

Um modelo de legitimidade, assim, é uma teorização sobre quem (sujeito) deve determinar o que é legítimo (objeto), com base em qual conjunto de valores e crenças.

O problema que isso coloca no contexto da tradição política anarquista, contudo, está na essência da legitimidade. Se esta é ausência de dissenso - ou aquilo que justifica a violência contra aqueles que discordam, produzindo tal ausência - ela pode ser utilizada por Estados (incluindo governos representativos) contra os questionamentos ácratas à ideia de governo. Seria preciso assim justificar por que anarquistas deveriam reclamar para si qualquer noção de legitimidade quando esta poderia tão facilmente ser identificada aos atos (repressivos) do Estado, embora este movimento já implique a discussão vindoura: que tipo de legitimidade anarquistas poderiam reclamar.

Essa discussão começa pela consideração de que a legitimidade em si pode ser uma dominação - no sentido da discussão que autores identificados como "pós-modernos"2 promovem sobre a questão: encerrar conflitos envolve impor a identidade à diferença, consenso à diversidade, e unidade à multiplicidade; todo não-conflito seria, na verdade, um conflito em disfarce, e portanto não existiriam não-conflitos. Como observa Cohn (2006, p. 202), a democracia promete transformar uma multiplicidade em uma pluralidade

2 Há provavelmente tantos pós-modernismos quanto pós-modernos (FEATHERSTONE, I988 apud ROSENAU, I992, p. I5). Discuto o tema a partir da perspectiva de Hatab (I995, cap. um). 


\section{C) Hitcostórica}

produtiva, mas a partir do prisma pós-moderno ela "nunca pode fazê-lo", já que "a persuasão pacífica e a deliberação pública” são na verdade "uma guerra”. É como se os pósmodernos chegassem à mesma conclusão dos ditos "realistas" (é impossível encerrar conflitos sem o uso da força), mas se recusassem a dar o último passo, isto é, legitimar um método de encerramento de conflito. Isto ocorre porque o problema dos ditos "realistas" é o consenso pacífico, enquanto o dos pós-modernos é qualquer acordo que se coloque como consenso necessário ou recomendável; uma vez que a legitimidade é impossível em qualquer nível, o gesto de seu estabelecimento não faz sentido.

Assim, segundo essa visão, anarquistas não deveriam reivindicar para si a legitimidade, pois ao fazê-lo estariam construindo uma dominação na medida em que o conflito seria dissimulado na forma de um "acordo". A dominação seria compreendida principalmente como ideológica. Newman (200I, p. 63) argumenta que "o que é importante" numa análise do Estado "não é a instituição em si", mas a maneira como funcionam em particular os "locais [...] através dos quais ele opera" - como os conceitos de "essência humana ou [de] homem". Embora autores pós-modernos afirmem o caráter constitutivo do "poder", nem sempre fazem referência a aparatos centralizados e organizados de violência, mas a dinâmicas e pressuposições do cotidiano, das relações entre indivíduos, que dão origem a práticas autoritárias e hierárquicas (estas, por sua vez, acumular-se-iam em fenômenos como o Estado). A análise da violência, da "força bruta", perde importância neste cenário.

Porém, a questão não envolve somente atos episódicos de violência, mas sua ameaça, "e os tipos de relações sociais que ameaças pervasivas de violência tornam possíveis" (GRAEBER, 20I5, p. 67). Isso é central ao pensamento anarquista: "Abolir a autoridade significa abolir o monopólio da força e da influência”, afirma Malatesta (1999, p. 76-77), mas para além de fazer com que o Estado desapareça, seria necessário simultaneamente cultivar outras instituições, práticas, ideias e valores para que a violência não retorne (ZABALAZA ANARCHIST COMMUNIST FEDERATION OF SOUTHERN AFRICA, 2003). O monopólio da violência é um aspecto importante, para anarquistas, das opressões identificadas por pós-modernos nas práticas representacionais. Representações encorajam as pessoas a conceber a si mesmas através do discurso de terceiros, mas a palavra-chave é encorajam. Se não há um aparato de violência centralizado construindo e reproduzindo à força desigualdades fundamentadas em determinadas representações, a representação em si não quer dizer muito; eu posso "encorajar" uma pessoa a conceber a si mesma de maneira negativa, o que de maneira geral consideramos reprovável em nossas 


\section{C) GitistóróRICA}

interações sociais cotidianas (o chamamos de "xingamento"), mas isto não pode ser considerado uma dominação (ou uma ofensa relativa a uma), a não ser que relações de violência adicionais (ou mais amplas, socialmente falando) estejam em funcionamento.

Se anarquistas discordarem de pós-modernos quanto a isso e compreenderem a legitimidade diversamente, esta se trataria de construir uma aceitação quanto a certos princípios, valores e propostas. Não fazê-lo seria simplesmente intervir sobre a realidade sem diálogo com pessoas que não compartilhem perspectivas - o que tanto poderia prejudicar a eficácia e a continuidade desse projeto de intervenção quanto exigir o uso de um tipo de violência que seria interpretado como análogo à violência sistêmica que constitui a dominação. Nesse sentido, anarquistas só poderiam reclamar a legitimidade para si se esta for uma legitimidade diametralmente oposta ao modelo de legitimidade proposto por teorias que pressupõem ou defendem a noção de Estado: uma legitimidade em que o uso da força não é legitimado3.

\section{Modelo geral de legitimidade anarquista}

Para compreender assim a possibilidade de modelos anarquistas de legitimidade, é fortuito compará-los aos modelos de legitimidades encontrados em tradições políticas nãoanarquistas.

O primeiro modelo identificável envolve uma coletividade (sujeito) estabelecendo um não-conflito quanto ao encerramento violento de conflito (objeto), com base em um conjunto de valores e crenças; em outras palavras, confia-se ao Estado a tarefa de promover esses valores e crenças. Não é possível de antemão fixar ou limitar quais poderiam ser estes valores e crenças, pois aqui há uma infinita variabilidade - pode-se tratar de orgulho nacional, de prosperidade material, de piedade religiosa, de supremacia militar, de grandeza cultural, e assim por diante. Como visto acima, tenta-se encerrar conflitos para alcançar situações de ausência de conflito (ainda que não permanentes; ainda que essa seja a tarefa eterna da sociabilidade); no entanto, o problema não é só que fazer isso no contexto de um aparato centralizado de violência vai muito provavelmente envolver a adição de conflito ao sistema, mas que a própria intransigência quanto ao conjunto de valores (seja

\footnotetext{
3 Além disso, seria preciso rejeitar a visão pós-moderna quanto ao conflito como fundamento último da realidade - que exclui ou atrofia, sem muita justificativa, o aspecto cooperativo de qualquer representação do mundo (social). Como coloca Graeber (200I, p. 29), este é um erro: “Não há área da vida humana, em qualquer lugar, em que não se possa encontrar o cálculo auto interessado. Mas tampouco há qualquer lugar em que não se possa encontrar gentileza ou aderência a princípios idealistas: a questão é porque um, e não o outro, é colocado como uma realidade 'objetiva'”.
} 


\section{C) Hitcostórica}

qual for) evoca a ameaça de violência como solução. "O desenvolvimento de um Estado policial", colocam os anarquistas Landstreicher et al. (2006, p. 8), "tem sido um processo democrático, uma expressão da 'vontade do povo'”. Tanto o contexto material (a distribuição de poder) quanto ideológico (quais valores são adotados, e quão absolutamente são defendidos) importam e se reforçam mutuamente.

Os problemas que assolam esse modelo se refletem na riqueza das discussões da tradição ocidental de teoria política acerca da legitimidade. A ideia de um valor ou uma vontade fixa em relação a uma coletividade é difícil de sustentar - e daí justamente parte da força da crítica pós-moderna: a demonstração de que noções como "o povo quer algo" ou "a população valoriza isso" são frequentemente construções políticas que objetivam estabelecer ou manter dominações. Para além da inadequação de teorias da representação, o consentimento também é problemático: como observa Pateman (I979, p. I5), "a teoria do consentimento há muito tem se envergonhado" de não ser capaz de demonstrar "quem, quando, e como realmente e explicitamente consentiu ao Estado liberal democrático".

Uma solução é um segundo modelo, em que o sujeito da legitimidade deixa de ser qualquer coletividade e passa a ser teórico, abstrato - isto é, há uma explicação pela qual a legitimidade de um determinado sistema existe, esta explicação é racional e correta, e ela fundamenta tanto a obrigação de obediência quanto o direito do recurso à violência, por parte do Estado, para obtê-la e conservá-la. A tese sociológica de Beetham (I99I) é, assim, a tentativa mais ousada de despir esse modelo de quaisquer conteúdos culturais específicos, fundamentando obrigações e direitos a partir da injeção de uma dose de democracia sem, no entanto, qualquer recurso à subjetividade. Deixar a cargo do "povo" a decisão sobre a legitimidade ou não do sistema é perigoso: o ideal é ser capaz de explicar como a legitimidade existe independente do que as pessoas pensem acerca dela. Obviamente, o que as pessoas pensam importa, ainda, se apenas porque isto influencia seus atos - não obstante, esta opinião pode ser manipulada ou influenciada de várias maneiras; ademais, a aprovação do próprio modelo de poder implica definir a dominação como algo que não é intrínseco à concentração de poder no Estado, o que este tipo de legitimidade presume.

Um modelo anarquista de legitimidade teria portanto que apresentar uma legitimidade contextual, em que cada cenário exige uma construção contínua de nãoconflitos, estes sempre podendo ser revogados pelos indivíduos e implicando, assim, uma dinâmica de cooperação, interindividualidade, imaginação e diálogo, valores imprescindíveis para manter essa dinâmica estável ao longo do tempo. A legitimidade para anarquistas implica que indivíduos (sujeito) estabelecem um não-conflito contextual 


\section{C) Hitstótórica}

quanto ao encerramento não-violento de conflito (objeto), com base em uma ética própria - em especial a rejeição às hierarquias e o princípio de coerência entre meios e fins que definem a tradição anarquista.

É importante reiterar que isso implica uma reavaliação da própria ideia de "indivíduo", no sentido de que são eles que seriam considerados os sujeitos dos processos de legitimação. Não se trata aqui dos indivíduos-átomos neoliberais - que pós-modernos adotam implicitamente em suas teorizações - mas tampouco se trata de uma visão ingênua da natureza humana. Como coloca Cohn $(2002, \$ 9)$, para anarquistas os "seres humanos possuem iguais potenciais para 'sociabilidade' e 'egoísmo'”, e "nenhum desses potenciais é mais provável de ser expressado que o outro". Em uma outra formulação, que emprega termos diferentes mas leva a conclusões semelhantes, anarquistas veem a natureza humana como completamente social - e isso não implica que o desejo por autoridade e comportamentos egoístas estejam completamente ausentes, uma vez que se relacionam a padrões mais amplos de cultura e sociabilidade (ZABALAZA ANARCHIST COMMUNIST FEDERATION OF SOUTHERN AFRICA, 2003). Bakunin explicitamente afirma que "os defeitos e os vícios, o mesmo que as boas qualidades, são inatos", e que "tudo quanto se denomina vício e virtude humanos é absolutamente um produto da ação combinada da natureza e da sociedade" (BAKUNIN, 1978 apud LÓPEZ, 20I3, p. I5-I6); em outra ocasião, afirma que "interesses, tendências, necessidades, ilusões e mesmo estupidez, assim como atos de violência e injustiça" são "consequência das forças fatais na vida em sociedade" (BAKUNIN, I998, p. 77). Anarquistas sempre reconheceram que o poder não é apenas restritivo, mas também construtivo e constitutivo da experiência social; que o Estado não deveria ser visto como "uma coisa ou um fetiche que se pode quebrar para destruí-lo", sendo em vez disso "uma condição, uma certa relação entre seres humanos" que "destruímos [...] ao contrair outras relações"; em suma, que "nós somos o Estado, e continuaremos a sê-lo até termos criado" outras instituições (COHN, 2006, p. 69). A "habilidade de agir de forma livre e cooperativa não é algo que se possui naturalmente", argumenta Carrier (I993); mas “é também produto de um treino". Quanto à ligação entre a denúncia do "poder" e considerações sobre a natureza humana, Goodman (I968 apud COHN, 2006, p. 215) afirma que "devemos evitar a concentração do poder precisamente porque somos falhos", de modo que a questão não é "se as pessoas são 'boas o bastante' para um tipo de organização social", mas se uma organização social ajuda a "desenvolver as potencialidades da inteligência, graça, e liberdade" ou não. 


\section{C) Hitcostórica}

Assim, se o poder produz subjetividade, outras formas institucionais e organizacionais encorajam comportamentos diversos. Como critica Bakunin (1998, p. 77), considerar "a sociedade um agregado mecânico e artificial de indivíduos" é "não compreender a sociabilidade da natureza humana": no decurso de nossas interações, os interesses de outros indivíduos podem integrar os nossos de maneira não-reflexiva, isto é, nossos laços sociais operam de modo a criar uma intersubjetividade, ou uma subjetividade interindividual, de modo que embora ajamos (racionalmente) por conta de nossos interesses, esses interesses terão sido produzidos na interação uns com os outros e em resposta às necessidades, vontades e preferências uns dos outros. Isso não é o que ocorre naturalmente na ausência de um poder repressor; "a tendência de proteger os interesses de outros [...] não pode ser somente um sentimento inato... seus rudimentos estiveram sempre presentes no ser humano, mas [...] precisam ser desenvolvidos” (KROPOTKIN, I924 apud COHN, 2006, p. 58). Como observa Graeber (200I, p. 36-37), a sociedade ocidental "presume que a coisa mais importante quanto às pessoas é que cada uma é um indivíduo único", e portanto é preciso sempre "começar com os indivíduos" e tentar "entender como eles formam relações uns com os outros (produzindo assim algo que chamamos de 'sociedade')"; uma outra visão seria a de que "relacionamentos [vêm] em primeiro lugar”. A exclusão desse aspecto "social" da experiência subjetiva - precisamente o que anarquistas enfatizam - é mais uma refração da presunção de competitividade como o fundamento último de tudo; se o indivíduo é visto de forma abstrata, em total isolamento, tudo que ele faz "baseia-se somente em seu próprio ponto de vista subjetivo", afirma Pateman (1979, p. 25); “que outro ponto de vista existe para uma tal criatura?". Em outras palavras, “o raciocínio do indivíduo será completamente autointeressado", dependendo de seu julgamento subjetivo quanto à vantagem e ao lucro pessoais de cada ação, que só será tomada "se for julgada como sendo de benefício para si mesmo e sua propriedade". Nesse sentido, o sujeito do modelo anarquista de legitimidade é o indivíduo, porém diferentemente concebido.

\section{Modelos de assembleia e de rede}

A partir do modelo geral de legitimidade anarquista surgem dois submodelos que representam diferentes enfoques e interpretações dos princípios ácratas, geralmente associados a diferentes vertentes do movimento anarquista: o modelo de assembleia e o 


\section{C) Hitcostórica}

modelo de rede. Ao avaliá-los, será possível entender como o princípio de ação direta ${ }^{4}$ os vincula à tradição como um todo e os compatibiliza, a despeito de suas diferenças.

Se para anarquistas sua própria organização (meio) precisa estar em consonância com seus valores (fins), alguns deles interpretam que todo grupo precisa ter o máximo de liberdade possível para tratar os procedimentos como ferramentas, alterando-os quando preciso; já para outros, algumas ferramentas são indispensáveis à proteção de uma situação de nãodominação. Outra questão importante (que inclusive incide sobre a anterior) é a fixidez das identidades. Em um lado do contínuo, há autores e movimentos que gostariam de ver uma sociedade que tem espaços decisórios fixos, populares e de base territorial, federados a níveis regionais (PRICHARD, No prelo, p. 7-8). No entanto, outros veem a "subsidiariedade" envolvida nesse projeto - a sociedade deveria ser organizada "de baixo para cima, pela livre associação [...] primeiro em associações depois em comunas, em regiões, em países e [...] numa grande federação internacional e universal” (BAKUNIN, I998, p. 76) - como antecessora do princípio de autoridade, e a necessidade de se organizar em uma instituição de identidade fixa em si uma presunção de unidade que não faz jus à multiplicidade do real. Enquanto os primeiros veem como indispensáveis a união popular e o tipo de política que combata diretamente asserções de privilégio e concentrações de poder - por meio, por exemplo, de decisões majoritárias - os segundos veem como mais importante garantir formas de preservar a independência individual, ou minoritária, em meio a processos coletivos.

Debates sobre modelos organizacionais entre anarquistas têm aumentado, em particular, desde o movimento Occupy, que para Prichard (No prelo, p. 20), desenvolveu "mecanismos institucionais e decisórios altamente sofisticados, horizontais e sensíveis às assimetrias de poder que interseccionavam com o movimento". Havia, de fato, uma série de espaços que "checavam" uns aos outros e que garantiram "que nenhuma única instituição ou voz coletiva fosse a voz final, e em vez de tomar a multidão pelo coletivo, ela a desagregou e institucionalizou uma consciência plural". A dinâmica do chamado "processo decisório com base em consenso" estabelece não um grupo cuja identidade é tão vinculante ("aceito, mediante este contrato social, agir conforme o grupo determinar") que as discussões digam respeito a como moldar as ações das pessoas, mas sim um fórum de apresentação de propostas não só para que pessoas encontrem outras com ideias semelhantes, mas que possam encontrar proposições diferentes - o que pode contribuir com melhores propostas. Apresentar algo que não é em última instância aceito, pelo resto 


\section{C) HitcostórRICA}

do grupo ou pela maioria, não é ser desrespeitado enquanto membro do grupo, pois não há na natureza do grupo a expectativa de que todos sejam obrigados a aceitar tudo que for dito dentro dele como proposta de ação a qual todos se comprometem (ainda assim, talvez seja um sinal de que alguma pessoa foi erroneamente identificada, por si mesma ou por outros, como parte do grupo). Em outras palavras, o processo decisório com base em consenso é uma forma de chegar a comprometimentos coletivos; ele é preconizado por muitos anarquistas como o melhor método decisório fundamental para uma identidade (construída em torno de um problema comum) porque é o que melhor ativa a inteligência e a criatividade de grandes grupos para chegar a soluções que não sejam inaceitáveis para nenhum membro, e o que não ativa dinâmicas competitivas que podem levar à aprovação de uma lógica de autoridade. Se um dos membros propõe algo que é inaceitável para algumas pessoas, a proposta tem que ser no mínimo re-elaborada para gerar um comprometimento comum; se essa pessoa é intransigente em relação ao que as pessoas devem fazer e não aceitar esses termos, ela deve poder reformular sua identidade no sentido de sair do grupo e fazer seu próprio caminho. Do mesmo modo, se uma proposta inaceitável para alguém vira um comprometimento comum - atrelando assim a identidade do grupo a essa ação - o mesmo deve ser possível para essa pessoa.

Nesse sentido, como entender o majoritarismo (típico do funcionamento clássico de assembleias) utilizado e elogiado ao longo da história do anarquismo, especialmente no âmbito do sindicalismo? Ou, ainda, na outra ponta do debate, a recusa ao processo de consenso? Em parte, o que explica essas diferenças é a questão identitária. Quando autores pós-modernos contestam a noção de identidade, apontam precisamente para a forma como ela pode motivar uma dinâmica de dominação. Se a identidade é imutável, não resta opção às minorias em um processo decisório: elas precisam acatar a decisão da maioria, a não ser que queiram se separar e constituir outro grupo - o que a imutabilidade da identidade torna impossível a priori, e em muitos sentidos na prática também, pois essa opção nem sempre pode estar disponível. Comunidades relativas à localidade em que se mora são um exemplo.

Uma dinâmica como essa concentra poder não exatamente em indivíduos, concedendo a uma minoria controle sobre aparatos de coerção, mas em "locais" (como papeis ou objetivos institucionais) identificáveis como pontos mais prováveis a partir dos quais efetivar interesses autorreferenciados, o que por sua vez ativa uma lógica de competição por esse local, subvertendo a dinâmica de cooperação e enfraquecendo a necessidade de intersubjetividade à medida que o indivíduo, ao operar em um campo 


\section{C) Hitcostórica}

competitivo, percebe cada vez mais a si mesmo e aos outros como os sujeitos atomizados do mercado (ou da guerra). É em oposição a esse "retorno do poder" que outras abordagens sugerem um modelo de atuação em rede, criando assim "coletividades complementares em cada nível da sociedade - espaços em que as pessoas se identifiquem umas com as outras e tenham razões para agir de forma justa uns com os outros"; nesse modelo, a mudança de instituições e regras "não precisa ser um sinal de fracasso", porquanto esses espaços não tratam da busca pela unanimidade ou concordância, mas sim por oportunidades "para que diferenças surjam, para que conflitos se desenrolem, e transformações ocorram à medida que diferentes constelações sociais convergem e divergem" (CRIMETHINC, 20I6).

O majoritarismo é visto como valioso pelo motivo oposto: a intersubjetividade da comunidade seria o suficiente para gerar processos que, mesmo majoritários em algum ponto final, não deixariam uma dinâmica de concentração de poder ressurgir — isto é, identidades presumidas (o proletariado, os cidadãos de uma cidade, ativistas ambientais) não poderiam ser sequestradas por minorias. Unidas por propósitos e sentimentos comuns, seus membros não perceberiam derrotas em assembleias como desrespeitos, mas colocariam a decisão dos demais acima de suas próprias vontades, especialmente se tivessem a plena oportunidade de expor seus pontos de vista em um debate franco. Há uma razão estratégica também para este modelo: seria necessário que essa identidade permaneça unida por conta da força dos números, pois somente quando as pessoas seguem juntas, fortalecendo-se em contraposição à própria ideia de concentração de poder, que o anarquismo poderia vencer enquanto senso comum político e se sustentar como base da vida de uma comunidade ao longo do tempo. Na medida em que um modelo de rede favorece a liberdade do indivíduo de constantemente reformular suas identidades, é como se o incentivasse a considerar com menos cuidado as consequências de deixar de somar forças, e incentivasse outros a não buscar o consenso já que a alternativa - deixar que alguém saia do grupo - seria naturalizada. Isso enfraqueceria o grupo, especialmente perante adversários (internos ou externos) autoritários. Para os defensores de modelos de rede, "se queremos construir espaços de liberdade, não podemos nos tornar tão fraturados a ponto de não conseguir defender esses espaços"; por outro lado, "não devemos resolver conflitos de maneiras que criem novos desequilíbrios de poder" (CRIMETHINC, 20I6). Para defensores do modelo de assembleia, esse não é um equilíbrio possível; é precisamente uma posição exageradamente individualista que levará à eventual legitimação de autoritarismo. 


\section{C) Hitstótórica}

De qualquer modo, a ação direta pode ser vista como o elemento transversal entre as diversas vertentes anarquistas, explicando como elas podem compartilhar um mesmo modelo de legitimidade, ainda que não um mesmo modelo organizacional. Afinal, já que se trata de um meio, o princípio ético anarquista de coincidência entre meios e fins exige que deva ser também um fim. Assim, o modelo de assembleia pode ser praticado a partir do comprometimento coletivo emergente de uma dinâmica fundamental, pregressa, de consenso quanto a uma identidade (quanto ao que une o grupo, como condições, histórias ou propósitos comuns). Não obstante, a dissidência de um grupo minoritário não pode ser tratada como uma "traição" - a minoria não pode ser excluída da "ideia de povo", seja lá no que esta se basear em um determinado grupo, e caçada por seu sectarismo. Se a ação direta é sempre uma possibilidade, a dissidência deve antes ser tratada como uma manifestação de ilegitimidade que informa a comunidade sobre si mesma, exigindo novos acordos com vistas à recuperação de uma identidade estável que volte a promover a ação comum. Esta legitimidade, contudo, não pode ser construída por meios violentos; é preciso encontrar estratégias de gerar não-conflito por meio de novos diálogos e convivências. Se a unidade for exigida sob ameaças de uso de força em nome da maioria e/ou da coletividade, reintroduz-se uma dinâmica de poder.

Proponentes de modelos de rede gostariam que a ação direta não fosse uma temida marca de ilegitimidade, que surge em momentos de exaustão do sistema e causa crises, mas, pelo contrário, buscam fazer dela a prática mais cotidiana da política produzida em uma sociedade ácrata. Isso representa uma concepção menos fixa de identidade, uma menor possibilidade de controle do que resulta da capacidade social, porém um maior risco de que concentrações de poder ocorram antes que possam ser checadas pela dinâmica das diversas ações diretas simultâneas.

Por fim, a questão da violência também fratura posturas anarquistas. Embora a ilegitimidade deva ser tratada como um fato político que provoca a reconstrução da legitimidade por meios não-violentos, isso não significa que nenhum anarquista faça uso da força ou aprove seu uso - apenas que, considerando o que a legitimidade significa, não há um não-conflito quanto a isto. Um modelo de legitimidade trata de uma lógica a partir da qual as pessoas esperam construir estabilidade, isto é, a ausência de conflito. Mas diferentemente de outras tradições políticas, para anarquistas a legitimidade não se trata de pacificar quanto ao uso da força, mas de problematizá-lo. Mesmo quando esta se faz necessária, assim, não há legitimidade: o desafio se torna encontrar maneiras de não transformar um princípio de violência imanente (como resistência contra a dominação), 


\section{C) HitistórRICA}

em um princípio transcendental, valorizado em si mesmo a despeito das circunstâncias. Falar de legitimidade é também falar do que é ilegítimo (ZELDITCH JR., 200I, p. 50), daquilo quanto ao que há de fato conflito na sociedade; embora uma noção de legitimidade oriente esforços coletivos, colocar a própria legitimidade, ou estabilidade, ou "paz", acima de tudo, não é a posição ética anarquista. A posição ácrata visualiza um mundo livre e igual, não um planeta em que estruturas de desigualdade, injustiça e violência permaneçam fixas ou mudem lentamente por conta do medo do que ocorreria se as coisas que parecem certas hoje não o sejam mais amanhã.

\section{Considerações finais}

Partindo da legitimidade como uma relação entre um sujeito, um objeto e um conjunto de valores e crenças, que estabelece o não-conflito, podemos verificar como anarquistas conformam um modelo geral de legitimidade próprio: indivíduos (para além dos moldes neoliberais através dos quais estes são geralmente conceituados), com base nos valores éticos do rechaço a formas de dominação e hierarquia e da coincidência entre meios e fins, buscam a instituição de mecanismos de resolução não-violenta de conflitos.

Isto pode ser realizado em diversas configurações, que podemos organizar em dois grandes submodelos: o modelo de assembleia e o modelo de rede. No modelo de assembleia, há uma maior identificação entre os princípios e as práticas/ferramentas dos processos decisórios, além de uma maior consideração quanto à fixidez das identidades envolvidas no processo, o que costuma implicar medidas como um federalismo de representantes delegados (isto é, de mandato imperativo e revogável) e processos de voto majoritário nos níveis mais locais. Já o modelo de rede preconiza uma maior liberdade para experimentar outros métodos, e considera uma fluidez maior das identidades, sendo geralmente identificado com alguma versão de processos decisórios baseados em consenso e reconhecendo a possibilidade de dissensos que provoquem a separação dos envolvidos com vistas à criação de espaços alternativos.

O que os une é um reconhecimento de que os processos têm por objetivo a estabilidade imprescindível às ações coletivas e coordenadas, mas sem recurso à violência de modo que a ação direta, verdadeiro arauto da ilegitimidade, seria tratada como sintoma de um problema social mais profundo que precisa ser resolvido sem que a violência seja legitimada. Não se trata do alcance de uma utopia em que a violência seria para todo o sempre extirpada da face da terra, mas do estabelecimento de uma compreensão moral 


\section{C) Hitcostórica}

compartilhada de que ela é um conflito, e jamais pode ser sistematicamente "justificada" enquanto ferramenta de resolução de conflito; seu emprego como autodefesa pode ser justificado porquanto evita uma situação de dominação (muito próxima a um cenário em que certos agentes adquirem a capacidade para criar e fortalecer uma dinâmica em que a violência é justificada), mas não é em si uma forma de resolver o conflito: há que se verificar quais são as interações sociais que estão levando à emergência destes conflitos e, através de um processo não-violento de diálogo e decisão, construir alternativas.

\section{Referências}

BAKUNIN, Mikhail. Escritos de Filosofía Política. Madri: Madrid Alianza Editorial, 1978.

BAKUNIN, Mikhail. A Igreja e o Estado. In: WOODCOCK, G. (Ed.). Os grandes escritos anarquistas. São Paulo: L\&PM, 1998. p. 75-8I.

BEETHAM, David. The legitimation of power. Nova Iorque: Palgrave, I99I.

BOBBIO, Norberto.; BOVERO, Michelangelo. Sociedade e Estado na Filosofia Política Moderna. São Paulo: Brasiliense, 1987.

BUCHANAN, Allen. Political legitimacy and democracy. Ethics, The University of Chicago Press, v. II2, n. 4, p. 689-719, 2002. Disponível em: <https://tinyurl.com/ya548fsh>.

CADEMARTORI, Sergio. Estado de Direito e Legitimidade - Uma Abordagem Garantista. Tese (Doutorado) - Universidade Federal de Santa Catarina, 1997.

CARRIER, Ron. Anarchism and power. 1993. Disponível em: <https://tinyurl.com/y8gq44r2>. Acesso em: 8 janeiro 20I7.

COHN, Jesse S. Anarchism and the crisis of representation: hermeneutics, aesthetics, politics. Selingsgrove: Susquehanna University Press, 2006.

CRIMETHINC. From Democracy to Freedom. 20I6. Disponível em: $<$ https://tinyurl.com/y7a5dko8>. Acesso em: II janeiro 2018.

GOODMAN, Paul. People or Personnel: Decentralizing and the Mixed Systems and Like a Conquered Province: The Moral Ambiguity of America. Nova Iorque: Vintage Books, 1968.

GRAEBER, David. Toward An Anthropological Theory of Value: The False Coin of Our Own Dreams. Nova Iorque: Palgrave, 2001.

GRAEBER, David. Fragmentos de uma antropologia anarquista. Porto Alegre: Deriva, $201 \mathrm{.}$ GRAEBER, David. The Utopia of Rules: On Technology, Stupidity, and the Secret Joys of Bureaucracy. Brooklyn: Melville House, 2015.

GRAHAM, R. (Mis)Conceptions of Anarchism. Anarchist Studies, v. 26, n. 2, outono 2018. 


\section{C) Hitcostórica}

HATAB, Lawrence. A Nietzschean Defense of Democracy: An Experiment in Postmodern Politics. Illinois: Open Court Publishing Company, 1995.

KINNA, R. The Government of No One. Londres: Pelican Books, 2019.

KROPOTKIN, Piotr. Ethics: Origin and Development. Dorset: Prism Press, 1924.

LANDSTREICHER, W. et al. This is What Democracy Looks Like. 2006. Disponível em: <https://tinyurl.com/ygt3b35r >. Acesso em: 30 janeiro 2018.

LÓPEZ, Fábio López. Poder e Domínio: Uma visão anarquista. São Paulo: Faísca Publicações Libertárias, 2013.

MALATESTA, Errico. A Anarquia. São Paulo: Editora Imaginário, 1999.

NEWMAN, Saul. From Bakunin to Lacan: Anti-authoritarianism and the dislocation of power. Lanham: Lexington Books, 200I. (G - Reference, Information and Interdisciplinary Subjects Series).

NEWMAN, Saul. The Politics of Postanarchism. Edimburgo: Edinburgh University Press, 2010 .

Ó LAOGHAIRE, Tadhg. Republicanism, Anarchism and the Pursuit of Non-Domination. Dissertação (Mestrado) — Leiden, 2016.

PATEMAN, Carole. The problem of political obligation. Nova Iorque: Wiley, I979.

PETTIT, Philip. On The People's Terms: A Republican Theory and Model of Democracy. Cambridge: Cambridge University Press, 2012.

POLIN, R. Analyse philosophique de l'idée de légitimité. In: L'Idée de Légitimité. Paris: PUF, 1967.

PRICHARD, Alex. Anarchism and Global Ethics. Londres: Routledge, No prelo. Disponível em: $<$ https://tinyurl.com/ycnftltm $>$.

RAWLS, John. Political liberalism: Reply to habermas. The Journal of Philosophy, Journal of Philosophy, Inc., v. 92, n. 3, p. 132-180, 1995.

ROCKER, Rudolf. Anarchism and Anarcho-Syndicalism. 2009. Disponível em: <https://tinyurl.com/ybk4qyh8 >. Acesso em: 25 janeiro 2018.

SILVA, Peterson R. "Intersecções e divergências entre a desobediência civil e o conceito libertário de ação direta”. Dissonância: Revista de Teoria Crítica, AOP (Advance Online Publication), p. I-34, Fevereiro de 2020.

SUCHMAN, Mark C. Managing legitimacy: Strategic and institutional approaches. Academy of Management Review, v. 20, p. 57I-6IO, 1995.

TYLER, Tom R. A psychological perspective on the legitimacy of institutions and authority. In: JOST, J. T.; MAJOR, B. (Ed.). The Psychology of Legitimacy: Emerging perspectives on 


\section{G) Citsơ Tórica}

ideology, justice, and integroup relations. Cambridge: Cambridge University Press, 200I. p. $416-436$.

TYLER, Tom R. Psychological perspectives on legitimacy and legitimation. Annual Review of Psychology, v. 57, n. I, p. 375-400, 2006.

WEBER, Max. Economy and Society. Londres: University of California Press, 1978.

WILLIAMS, Bernard; HAWTHORN, Geoffrey. In the Beginning was the Deed: Realism and Moralism in Political Argument. Princeton: Princeton University Press, 2005.

WILSON, M. Rules without rulers: The possibilities and limits of anarchism. Tese (Doutorado) Loughborough University, $201 \mathrm{.}$

ZABALAZA ANARCHIST COMMUNIST FEDERATION OF SOUTHERN AFRICA. Sucking the Golden Egg: A Reply to Newman. 2003. Disponível em: $<$ https://tinyurl.com/yak9ccny>. Acesso em: Io janeiro 2018.

ZELDITCH JR., Morris. Theories of legitimacy. In: JOST, J. T.; MAJOR, B. (Ed.). The Psychology of Legitimacy: Emerging perspectives on ideology, justice, and integroup relations. Cambridge: Cambridge University Press, 200I. p. 33-53.

Recebido em: I4 de julho de 2020

Aprovado em: 3I de maio de 202I 